\title{
CODE-SWITCHING AND CODE-MIXING PRACTICES IN ENGLISH FOR SPECIFIC PURPOSES (ESP) COURSES
}

\author{
Liza Amalia Putri ${ }^{1}$, Herly Nurrahmi ${ }^{2}$, Akhmad Guntawan ${ }^{3}$ \\ Politeknik Negeri Media Kreatif 123 \\ liza.aputri@polimedia.ac.id ${ }^{1}, \underline{\text { herly.nurrahmi@polimedia.ac.id }}^{2}$, \\ akhmad.guntawan@polimedia.ac.id $^{3}$
}

\begin{abstract}
This study focuses on the practices of the ESP (English for Spesific Purposes) lecturer and students toward code-switching and code-mixing (CS/CM) in the class activity. The study used descriptive qualitative method in the research. In collecting the data, the researcher shared some questionnaires and did interviews and observation. It provides the clear findings of the actual implementation of the institutional language policy on the medium of instruction in the classroom. CS/CM in both Indonesian and English languages emerged as the lecturer's code choice in the classroom instruction. Such language practice seems not to only have undermined the role of English as the stipulated medium of instruction, but also underestimated the speech behaviour of bilinguals. It causes the conflict between the language policy and the actual use of English and Indonesian in the classroom.
\end{abstract}

Keyword: ESP, code switching, code mixing

\section{BACKGROUND}

In a bilingual or multilingual society, it is normal for people to be in a situation where a choice between two or more languages/codes has to be made (Putri and Clayton, 2020). Marjohan (1998:48) says "code is a term which refers to a variety". Thus, a code maybe an idiolect, a dialect, a sociolect, a register or a language. Code switching and code mixing exist due to the impact of the ability and the skill of people to speak more than one language (Gardner, 2001). Code switching is a situation where speakers deliberately change a code being used, namely by switching from one to another. Code switching can be generally defined as the phenomenon where in a bilingual or multilingual speaker shifts from one language to another in the course of a conversation. Gal Wardaugh (1998:100) says "code switching is a conversational strategy used to establish, cross or destroy boundaries; to create, evoke or change interpersonal relations with their rights and obligations." On the other hand, code mixing is the mixing of pieces of a word or phrase from a language into the other language in a bilingualism or multilingualism. Code mixing refers to the mixture of two or more languages or language varieties in speech. Empirical studies have demonstrated that it is quite difficult to find ESP classroom discourse fully in a single language (Putri and Bustos, 2018). Even in a CLIL setting, other languages understood by the speakers is used, thus, switching and mixing between the languages are common (Ariffin and Misyana, 2011).

At present, most universities and colleges in Indonesia have ruled that the language of instruction in content subject classrooms to be English especially in English for Specific 
Purpose (ESP) courses, which becomes the main purpose of the subject (Sinar, Putri and Putri, 2019). The research was carried out to investigate the behaviour learning environment particularly the language used in the ESP classroom in various faculties of the state university in Indonesia. Although English has been prescribed as the medium of instruction, in reality, it has been observed that this policy has not been fully adhered to (Elfiki, 2009). A mixed code of English and Indonesian language, the latter being the mother tongue of most lecturers and students, is used extensively in most content-based lectures in the classrooms. This research explores the extent to which English and Indonesian language are mixed in the classroom instructions and students' practices towards this communicative behaviour. In particular, it concerns with students' perspectives of the language used in the classroom and its impact on their study and language development.

\section{RESEARCH METHOD}

The author used descriptive qualitative method in the process of explaining and interpreting the observation of this research (Gardner, 2001). The information on students' perception of the regularity of lecturers' $\mathrm{CS} / \mathrm{CM}$ practices while delivering lectures, and behaviours towards the language situation in the classroom were gleaned by using self-completed questionnaires and interviews.

The three primary sources for obtaining data are language-teaching, organizations, user-establishments, and the students (Appel and Musken, 2010). Throughout the procedure of information attainment, the author compiled some information including the students' training environment, their perception of learning and teaching process, approaches and systems, their needs and the availability of materials (Bloomfield, 2013).

\section{RESULTS}

The analysis of the data shows the pattern of language used by the lecturer. It seems that the extent to which CS/CM occurred in the classroom depended highly first, on the lecturer's competence in English, and also, the students' competence in English. The following result shows the students' perceptions on the frequency of their lecturer's CS/CM in the classroom.

1. Statement:

Mixing English and Indonesian is a common phenomenon in the lectures I have attended in this class

Response (Number of Students):

Strongly Agree $\quad 30$

Agree $\quad 20$

Disagree $\quad 10$

Strongly Disagree 0

2. Statement:

The lecturer's language when

delivering lectures is always English.

Response (Number of Students):

Strongly Agree $\quad 24$

Agree $\quad 16$

Disagree 12

Strongly Disagree 8

3. Statement:

The lecturer frequently mixes

Indonesian with English in his

lectures.

Response (Number of Students):

Strongly Agree $\quad 16$

Agree 20

Disagree 8

Strongly Disagree $\quad 12$

4. Statement: 
The lecturer usually maintains the English terminology but uses

Indonesian to give further

explanation.

Response (Number of Students):

Strongly Agree $\quad 20$

Agree 14

Disagree 12

Strongly Disagree 14

5. Statement:

The lecturer doesn't have any

difficulty in delivering lectures in

English.

Response (Number of Students):

Strongly Agree 24

Agree 26

Disagree 6

Strongly Disagree 4

6. Statement:

The lecturer always switches to

Indonesian when we do not

understand the lectures.

Response (Number of Students):

Strongly Agree 22

Agree 28

Disagree $\quad 10$

Strongly Disagree 0

The data reveal the clear pattern of lecturer's language use in the classroom. More than half of the students claimed the use of both Indonesian and English for classroom instruction was a common practice in the institution. In fact, the interview data reveal that the mixture of Indonesian and English was very common in most of the lectures they attended that they barely realised the occurrence during the lessons. Some even claimed that it is expected since the mixing of both languages in communication is common among bilingual speakers in any context of communication.

The analysis also reveals that the amount of CS/CM in classroom was largely related to the lecturer's and students' English Language competence. It is found that the CS/CM phenomenon occurred more in the class as the lecturer for the class was less proficient in English. The data show that the lecturer normally maintained the English terminology and technical jargons related to the topics taught. The students also claimed that English was used when the lecturer read directly from the notes or the power point presentation. However, when it comes to elaboration and explanation of the concepts, he tended to code-switch to Indonesian or code-mix both English and Indonesian.

However, some of the students also admitted that the proficient lecturer insisted in delivering their lectures in English and encouraged students to improve their English Language competence in order to cope with any language difficulties they might face. This is clearly reflected in the low frequency of CS/CM by proficient lecturer as shown in both tables. It is very important to note that lecturer's own proficiency level could not account for the actual language use in the context of interaction. It is found that even the proficient lecturer was not able to maintain their speech in English and have to resort to Indonesian because they needed to accommodate students who were not competent in English. This is reflected that despite their proficiency in English, the proficient lecturer frequently mixed Indonesian and English in their speech when they perceived students were not able to understand the lectures in English. Interviews with the lecturer reveal that they were aware of the institutional language policy.

However, their language choice and use were largely determined by their own competence in English and 
their students. This had led to their CS/CM behaviour in the classroom instruction. The less proficient lecturer normally uses both Indonesian and English in his lectures. However, they would maintain the referential items in English as these were the key words that students needed to know for the concepts learned. On the other hand, the more proficient lecturer both gave explanation in English first and then translated it into Indonesian when required, or straight away mixed both languages in their explanation. However, he also maintained the referential items in English. These claims concur with the students' perceptions on the language use in the classroom.

The analysis of the data reveals mixed attitudes towards the lecturer's CS/CM behaviour in the classroom. These attitudes were largely influenced by the students' English Language competence. It seems that the less proficient students held more favourable attitude towards the lecturer's CS/CM compared to their more proficient counterparts. Their views are shown in the result below.

\section{Less Proficient Students}

1. Statement:

I would like the lecturer to minimise their use of Indonesian in his lectures.

Response (Number of Students):

Strongly Agree $\quad 10$

Agree 16

Disagree 14

Strongly Disagree 20

2. Statement:

I would prefer my lecturer to use

only English in his lectures.

Response (Number of Students):

Strongly Agree

Agree

10
Disagree 22

Strongly Disagree 24

3. Statement:

I need the lecturer to use both

Indonesian and English to better understand the lectures.

Response (Number of Students):

Strongly Agree $\quad 28$

Agree 24

Disagree 8

Strongly Disagree 0

4. Statement:

I feel challenged if/when the

lecturer uses English in his lectures.

Response (Number of Students):

Strongly Agree $\quad 34$

Agree 20

Disagree 6

Strongly Disagree 0

5. Statement:

I feel frustrated when the lecturer uses both Indonesian and English during his lectures.

Response (Number of Students):

Strongly Agree $\quad 0$

Agree 8

Disagree $\quad 32$

Strongly Disagree 20

6. Statement:

The lecturer's mixing of English and Indonesian is not a problem to me.

Response (Number of Students):

Strongly Agree $\quad 40$

Agree $\quad 12$

Disagree 8

Strongly Disagree 0

7. Statement:

When the lecturer mixes Indonesian and English in his lectures, I tune out.

Response (Number of Students):

Strongly Agree 6

Agree 12

Disagree 22

Strongly Disagree 20

More Proficient Students

1. Statement: 
I would like the lecturer to minimise their use of Indonesian in his lectures.

Response (Number of Students):

Strongly Agree $\quad 28$

Agree 18

Disagree 10

Strongly Disagree 4

2. Statement:

I would prefer my lecturer to use

only English in his lectures.

Response (Number of Students):

Strongly Agree $\quad 40$

Agree 6

Disagree 12

Strongly Disagree 2

3. Statement:

I need the lecturer to use both

Indonesian and English to better

understand the lectures.

Response (Number of Students):

Strongly Agree 4

Agree 24

Disagree 20

Strongly Disagree 12

4. Statement:

I feel challenged if/when the

lecturer use English in his lectures.

Response (Number of Students):

Strongly Agree 34

Agree $\quad 10$

Disagree 10

Strongly Disagree 6

5. Statement:

I feel frustrated when the lecturer uses both Indonesian and English during his lectures.

Response (Number of Students):

Strongly Agree 4

Agree 16

Disagree 22

Strongly Disagree 18

6. Statement:

The lecturer's mixing of English and Indonesian is not a problem to me.

Response (Number of Students): Strongly Agree
Agree 20

Disagree 8

Strongly Disagree 8

7. Statement:

When the lecturer mixes Indonesian and English in his lectures, I tune out.

Response (Number of Students):

Strongly Agree 0

Agree $\quad 10$

Disagree $\quad 30$

Strongly Disagree 20

The analysis of the data indicates that the students with less English Language proficiency were more tolerant to the lecturer's CS/CM compared to the more proficient group. It seems that the former group favoured the lecturer's CS/CM behaviour due to their concern in comprehending the lectures. CS/CM was favoured due to its necessity to aid comprehension. Although it was agreed that most materials and references are available in English, this group of students felt that their low English Language proficiency hindered comprehension. Thus, the lecturer's language choice seemed to be a practical solution to the problem. Although most of the students agreed that the use of Indonesian helped them to comprehend the lectures better, they also admitted that the use of English was also necessary to expose them to their subjects of studies. However, they were not concerned on how language was used in the classroom. This is because, in a content-based classroom, the focus is more on meaning rather than the structure.

On the other hand, the more proficient group held quite unfavourable behaviours towards the lecturer's CS/CM. They felt that the use of Indonesian language should be minimised as students should be more 
exposed to English language since most references are available in the language. Thus, switching from English to Indonesian language to solve comprehension problems did not seem to be a long-term solution for less proficient students. Comprehension problems might occur during self-study. This proficient group also claimed that any input received in English can prepare them not only for self-study, but also for their future career. It is very interesting to know that these students claimed that the lecturer's language of instruction can help them develop their English language competence to enable them to cope in the field of study. They further argued that if the lecturer used mixed languages to explain the concept, the explanation would devoid of the correct structure. In other words, they had not been provided with or exposed to the correct model of explaining the concepts in English. Thus, they certainly would face difficulties in the examinations where all answers are required to be written in English. They further argued that understanding the concept would not be adequate if they were not able to give the answers in the correct way. Thus, in contrast, the more proficient group felt that the lecturer should focus both on the meaning and the structure when delivering the lectures.

\section{CONCLUSION}

This study has provided clear findings of the actual implementation of the institutional language policy on the medium of instruction in the classroom. CS/CM in both Indonesian and English language emerged as the lecturer's code choice in the classroom instruction. Such language behaviour seems not only to have undermined the role of English as the stipulated medium of instruction, but also underestimated the speech behaviour of bilinguals. It causes the conflict between the language policy and the actual use of English and Indonesian in the classroom.

There is also an indication that both lecturer and students are not totally linguistically equipped to support the policy. Lack of English Language competence on some students has been claimed as the major motivating factor for the CS/CM occurrence. This certainly has a significant implication on their English Language development skills. As implied by the students' response, the language of teaching can affect the process of learning and acquiring knowledge. Thus, it seems to be an important need for the lecturer to pay more attention to the language used in delivering the content of the lectures to benefit the learning.

\section{REFERENCES}

Appel, R. and Musken, P. (2010). Language Contact and Bilingualism. Great Britain: Edward Arnold.

Ariffin, K. \& Misyana S.H. (2011). Code-switching and Codemixing of English and Bahasa Malaysia in Content Based Classrooms: Regularity and Behaviours in The Linguistics Journal. Universiti Teknologi MARA.

Bloomfield, L. (2013). Language. New York: Holt Rinehart, and Winston.

El-Fiki, H. A. (20099). Code-mixing of Arabic and English in a university scienceteaching

context: Regularity, grammatical categories and behaviors. Concordia University, Montreal, Quebec, Canada.

Gardner, R. \& M.P. (2001). An instrumental motivation in language study: Who 
says it isn't effective? Studies in

Second Language Acquisition Journal.

Marjohan, A. (1998). An Introduction to Sociolinguistics. Jakarta: Departemen Pendidikan dan Kebudayaan.

Putri, L.A. and Claytom, K. (2020).

The Identity Issue of the Colonized and the Colonizer in Cloud Nine by Caryl Churchill, International Journal of Cultural and Art Studies Vol. 4 No. 1 (p. 1-8).

Putri, L.A. and Bustos, J. (2018). Assessing the Process Not Just the Message: A Cursory View of Student Assessment, International Journal of Cultural and Art Studies Vol. 1 No. 1 (p. 19-27).

Sinar, T.S., Putri, L.A., Putri, D.M., (2019). Self-Assessment and Reflection in Portofolios Enhancing EFL Students' Writing. Elementary School Journal Vol. $9 \mathrm{~N}$

Wardaugh, R. (1998). An Intoduction to Sociolinguistics Third Edition.

Massachussetts: Blackwell Publisher Inc. 